\title{
Consanguinity and Primary Immunodeficiencies
}

\author{
Waleed Al-Herz ${ }^{a, b}$ Hasan Aldhekric ${ }^{c}$ Mohamed-Ridha Barbouche ${ }^{d}$ \\ Nima Rezaei ${ }^{e, f}$ \\ ${ }^{a}$ Department of Pediatrics, Faculty of Medicine, Kuwait University and ${ }^{b}$ Allergy and Clinical Immunology Unit, \\ Pediatric Department, Al-Sabah Hospital, Kuwait City, Kuwait; 'Section of Pediatric Allergy and Immunology, \\ King Faisal Specialist Hospital and Research Centre, Riyadh, Saudi Arabia; ${ }^{\mathrm{d}}$ Immunology Department,

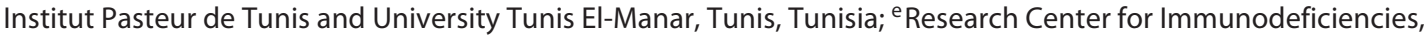 \\ Children's Medical Center and f Molecular Immunology Research Center, Department of Immunology, \\ School of Medicine, Tehran University of Medical Sciences, Tehran, Iran
}

\section{Key Words}

Consanguinity · Primary immunodeficiencies · Genes ·

Genetic counseling

\begin{abstract}
Primary immunodeficiencies (PIDs) are a heterogeneous group of genetic disorders caused by defects in the immune system that predispose patients to infections, autoimmune diseases, lymphoproliferation and malignancies. Most PIDs are inherited in an autosomal recessive pattern; therefore, they are more common in areas with high rates of consanguineous marriage. Reports about PIDs from these areas have demonstrated a peculiar prevalence of more severe forms of diseases compared to other regions, and patients born to consanguineous parents have increased rates of morbidity and mortality compared to other patients. Individuals at high risk of having a child with a PID who wish to have a healthy child have limited options, these include prenatal diagnosis and pre-implantation genetic diagnosis. However, these options require a collaborative team of specialists and may not always be implemented due to geographic, religious, financial or social factors. The recent intro-
\end{abstract}

duction of newborn-screening programs for a number of $T$ and B lymphocyte deficiencies will facilitate early diagnosis and therapeutic interventions, which may include hematopoietic stem cell transplantation and intravenous immunoglobulin treatment. There is a need for the implementation of strategies to increase public awareness of the health risks associated with consanguineous marriage. It should be stressed that genetic counseling should be an important component of the care of patients with PIDs as well as their families.

(c) 2014 S. Karger AG, Basel

\section{Introduction}

Primary immunodeficiencies (PIDs) are a heterogeneous group of genetic disorders caused by mutations in genes encoding immune system components, which lead to defects in the development and/or function of the immune system [1]. Such defects predispose patients to a wide spectrum of clinical manifestations and complications, in particular an increased susceptibility to infections, autoimmune diseases, lymphoproliferation and malignan-

\section{KARGER}

E-Mail karger@karger.com

www.karger.com/hhe
(C) 2014 S. Karger AG, Basel

0001-5652/14/0774-0138\$39.50/0
Waleed Al-Herz, MD

Department of Pediatrics, Faculty of Medicine

Kuwait University

24923 Safat, Kuwait City 13110 (Kuwait)

E-Mail wemh@hotmail.com 
cies. Although some PID patients show mild signs and symptoms, patients with severe PIDs, such as severe combined immunodeficiency (CID), usually do not see their first birthday if not diagnosed and treated urgently [2].

The Expert Committee for Primary Immunodeficiency of the International Union of Immunological Societies (IUIS) classified PIDs into 8 general categories: (1) CIDs, (2) well-defined syndromes with immunodeficiency, (3) predominantly antibody deficiencies, (4) diseases of immune dysregulation, (5) congenital defects of phagocyte number, function, or both, (6) defects in innate immunity, (7) autoinflammatory disorders, and (8) complement deficiencies. Approximately 200 different PIDs have been identified to date, and their number is still growing rapidly [3].

The true incidence and prevalence rates of PIDs are unclear. The overall prevalence of PIDs has been estimated as approximately 10:100,000 individuals; however, further reports indicated a higher prevalence of PIDs that differs throughout the world [4]. A recent study suggested that although approximately 60,000 patients with PIDs have been documented, approximately $6,000,000$ people are estimated to be living with PIDs worldwide, which suggests that PIDs are no longer rare [5].

\section{Inheritance of PIDs}

PIDs can be inherited in different patterns. The autosomal recessive (AR) pattern is the most common form of inheritance in patients born to consanguineous parents $[6,7]$. However, X-linked (XL) inheritance is prevalent in other regions, which leads to a higher disease rate in males. Some PIDs are inherited in an autosomal dominant pattern. Notably, assessing the precise family history is important for determining parental consanguinity, early deaths of siblings or similar symptoms in other family members. The presence of affected siblings in a family could suggest an AR inheritance, whereas transmission from parent to child can be observed in autosomal dominant inheritance. The presence of disease in only male individuals could be suggestive of an XL disorder.

\section{Consanguinity Worldwide}

More than 1,000,000,000 people live in regions of the world where consanguineous marriages are common, particularly marriages between cousins [8]. These consanguineous unions are particularly prevalent in the Middle
East and North Africa as well as in West Asia. The populations in these regions are made up of different ethnic origins. The rate of intra-familial marriage may differ there from one country to another and within the same country between geographic areas, but the overall percentage is between 20 and $50 \%$ of all marriages [9]. Although reliable data on the prevalence of consanguinity for many countries are not yet available, generally it does not exceed $1-10 \%$ [9] in most other regions of the world. Interestingly, consanguineous marriages are also practiced in Europe, North America and Australia among emigrant communities from highly consanguineous populations. In recent years, this brought new patterns of sociocultural diversity and associated criticisms as well as new public health concerns into awareness in the host countries [10].

In societies with specific local or tribal traditions, the tendency to prefer such unions is generally aimed at preserving family structure and property, strengthening relationships with in-laws and, consequently, bringing more stability and durability to marriages [8]. In addition to the impact of customs or laws associated with ethnic and cultural backgrounds, religious factors also contribute to the differences observed in the extent of this phenomenon between world regions as well as between and within different countries.

\section{Consanguinity and Genetics}

Consanguineous mating is known to be associated with a higher risk for AR diseases. This impact of inbreeding on health is attributed to the higher probability for offspring of consanguineous parents to be homozygous by descent and to inherit two copies of the same single allele than for those born to non-consanguineous parents. Recent studies based on high-density SNP genotyping have clearly shown a gradual increase in average genome-wide homozygosity with increasing levels of consanguinity [11]. Deleterious founder mutations have been reported in different consanguineous populations to be the underlying cause of a large spectrum of monogenic AR diseases including PIDs $[12,13]$. Recently, an interesting, but still controversial, potentially beneficial genetic aspect of consanguinity has been reported in the literature, suggesting that not only cultural and socioeconomic benefits may explain the origin and persistence of this behavior $[14,15]$. Indeed, it has been proposed that inbreeding may also increase the speed of selection of recessive alleles protecting against diseases such as malaria. This would allow a relative fitness of a population under 
particular ecological conditions, with a potential overall genetic benefit that might exceed the genetic cost of inbreeding [15].

\section{Impact of Parental Consanguinity on PIDs}

Unfortunately, the true prevalence of PIDs worldwide is not known; however, it is known to vary between populations from different geographic and ethnic backgrounds. Because most PIDs are inherited as AR traits, they would be expected to be more common in areas with high rates of consanguinity. Available reports from a few countries with high rates of consanguineous marriages have revealed a peculiar distribution of PIDs, with a predominance of severe forms such as CIDs and phagocytic dysfunction, which is in contrast to the predominance of antibody deficiencies in other populations [13, 16-21]. Furthermore, consanguineous marriages have also been found to affect the types of genetic defects causing these diseases. For example, deficiencies in major histocompatibility complex class II and recombinase-activating gene (RAG) 1 or 2, which are transmitted in an AR pattern, are the most common causes of CIDs in the Middle East, whereas defects in the IL-2 common $\gamma$ chain, which are $\mathrm{XL}$, are the most common cause of combined PIDs in other geographic areas and ethnicities [22]. Another example of differences in the genetic defects causing PIDs in different populations can be found in chronic granulomatous disease. Although XL chronic granulomatous disease represents approximately two-thirds of chronic granulomatous disease patients in Western countries [23], AR forms of the disease appear to be the most common in regions with higher rates of consanguinity [24, 25].

PID patients with a history of parental consanguinity have been found to present with more severe PID phenotypes, as documented by the high rates of complications and unusual infections [26,27], poor overall performance status [28], and a higher risk of death [29]. This could be due to an overrepresentation of more severe early-onset PIDs in these populations.

\section{Identification of Novel PIDs}

The number of human genetic disorders is continuously expanding. In the last 15 years, the molecular defects in approximately 200 PIDs have been defined, and a genotype-phenotype correlation has been established for some of them, with important prognostic and thera-
Table 1. Novel PID genes identified during the last 3 years by studying patients with a history of parental consanguinity

\begin{tabular}{lll}
\hline Gene & Disease & $\begin{array}{l}\text { Refer- } \\
\text { ence }\end{array}$ \\
\hline LRBA & CVID/CID & 33 \\
STK4 & CID & 34 \\
CD27 & CID/lymphoproliferation & 35 \\
ADAM17 & inflammatory skin and bowel disease & 36 \\
IL-36RN & generalized pustular psoriasis & 37 \\
TRIF & TRIF deficiency & 38 \\
ISG15 & predisposition to mycobacterial disease & 39 \\
ITK & CID & 40 \\
CARD11 & CID & 41 \\
TRAC & CID & 42 \\
MALT1 & CID & 43 \\
VPS45 & SCN5 & 44 \\
WIPF1 & WAS-like phenotype & 45 \\
IL-10R/IL-10 & early-onset IBD & $46 / 47$ \\
IL21R & CID & 48 \\
\hline
\end{tabular}

CVID = Common variable immunodeficiency disorders; IBD = inflammatory bowel disease; $\mathrm{SCN}$ = severe congenital neutropenia; WAS = Wiskott-Aldrich syndrome.

peutic implications [30-32]. Due to the availability of next-generation sequencing technology in recent years, families from areas with a high rate of consanguineous marriages have been important for the identification of novel and complex phenotypes associated with PIDs (table 1) [33-48]. Because most of these diseases are inherited as AR traits, the identification of patients with unique clinical and immunologic manifestations within large consanguineous families may enable the identification of novel disease-causing genes. Figure 1 shows an example of such a family, in which multiple subjects suffered from early-onset sinopulmonary infections. Laboratory testing demonstrated agammaglobulinemia, thrombocytopenia, intermittent neutropenia and mild anemia. The immunologic analysis of peripheral blood mononuclear cells revealed normal percentages of $\mathrm{CD}^{+}$ $\mathrm{T}$ cells and CD19+ $\mathrm{B}$ cells, but a severely decreased percentage of $\mathrm{CD} 19^{+} \mathrm{CD} 27^{+}$memory B cells in the patients compared with healthy age-matched controls. The proliferation of peripheral blood mononuclear cells to several $\mathrm{T}$-cell mitogens and anti-CD3 was significantly decreased in the patients compared with the healthy controls. Eight patients were cured with hematopoietic stem cell transplantation from HLA-matched siblings. This family is currently studied using both linkage analysis and wholegenome sequencing to identify the culprit gene. 
Fig. 1. Pedigree of a large highly consanguineous family with multiple patients affected by a novel PID.

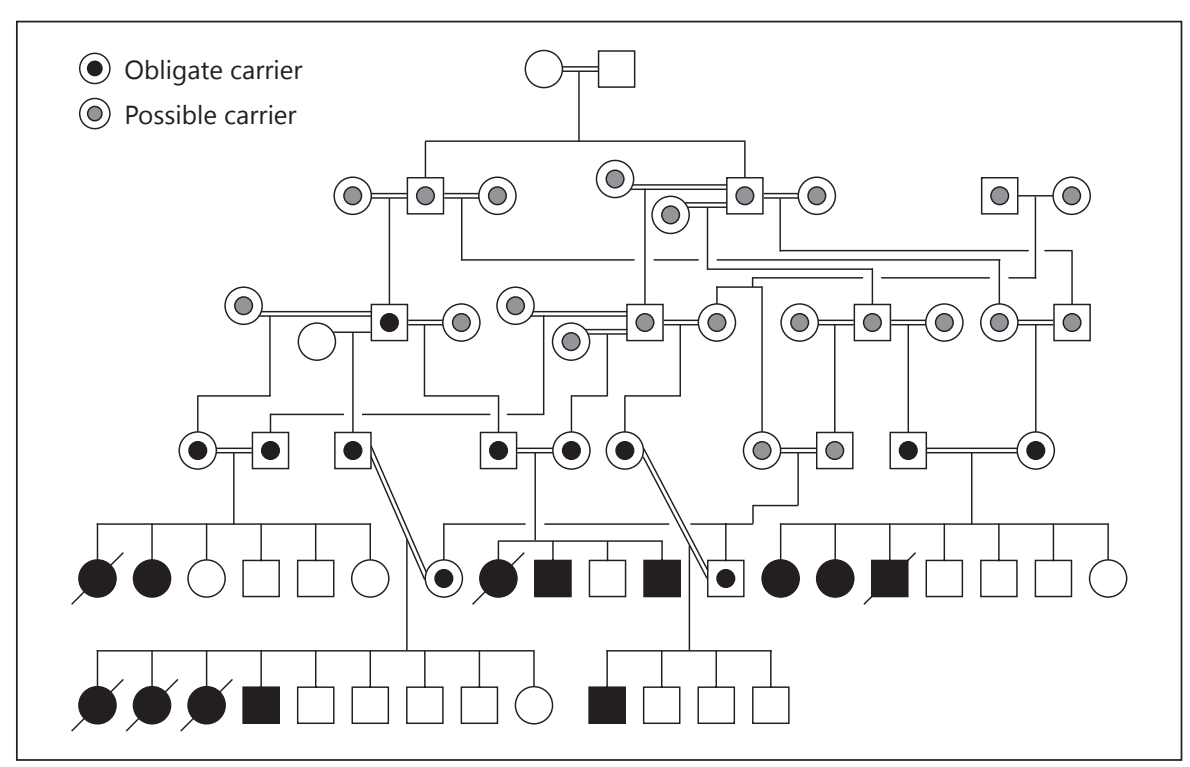

\section{Prenatal Diagnosis and Genetic Counseling}

The burden of PIDs on an individual or country level necessitates strategic planning to prevent them or reduce their prevalence [49]. The burdens vary between the different forms of PIDs but are higher in cases of CID, which are more common in countries with high rates of consanguineous marriage.

Families known to have PID patients with identified genetic mutations should be given the option of pre-marital carrier testing followed by genetic counseling. Individuals at high risk of having a child with the disease because they are carriers for the genetic defect have limited options. They may opt to have no more children, which may compromise the family and break it apart. They also have the option to undergo prenatal diagnosis (PND) and, in the case of an affected fetus, may decide to terminate the pregnancy, which is unacceptable in some cultures due to national laws or traditional or religious issues. Undergoing pre-implantation genetic diagnosis (PGD) to have healthy children is another option. However, these options require a collaborative team of immunologists, geneticists and genetic counselors, and the implementation of such interventions and access to genetic services may be limited due to geographic, religious, financial or social factors [50].

PND for PIDs involves testing the fetus or embryo for a known PID in the family to provide the option of pregnancy termination. In addition, it may give the family the chance to be prepared for the medical, psychological, fi- nancial and family implications of the disease as well as time to expedite the process of medical interventions and precautions. These may include hematopoietic stem cell transplantation, intravenous immunoglobulins, prophylactic antibiotics and the avoidance of live vaccines. Notably, PND requires that the disease-causing gene and mutation are known, and the procedure carries the risk of fetal loss.

PGD was introduced at the beginning of the 1990s as an alternative to PND to prevent pregnancy termination by couples with a high risk for having offspring affected by a genetic disease [51]. In this procedure, embryos created in vitro are analyzed for well-defined genetic defects, and only those with no genetic mutation are placed into the uterus. Embryos can also be selected according to their HLA type, so that the resulting child can serve as a stem-cell donor for an affected sibling. However, PGD carries the risks of misdiagnosis and pregnancy failure despite advances in technical applications.

\section{Future Perspectives: Neonatal Screening for PIDs}

Newborn screening (NBS) for a number of T and B lymphocyte deficiencies is now available and has already been implemented in a few countries [52,53]. NBS is performed using real-time polymerase chain reaction on DNA extracted from blood collected on NBS cards. T lymphocyte deficiencies such as severe CID can be detected using the T cell receptor excision circle (TREC) as- 
say, while kappa-deleting recombination excision circles (KREC) can detect abnormalities in B cell development in primary B cell immunodeficiencies [54]. Both tests were found to be cost effective and sensitive [55, 56]. Hence, their implementation in countries with a high frequency of PIDs is crucial and will remarkably improve long-term survival and decrease mortality for these disorders.

\section{Conclusions}

Despite the impressive changes in demographics, education and social behavior that have occurred over the last decades, consanguineous unions are still highly common in many countries and communities including those with favorable socioeconomic conditions and ad- vanced diagnostic and health care facilities. A decline in the prevalence of such unions would be normally expected. Indeed, in this period of epidemiological transition, the lower mortality and morbidity due to infectious diseases and increased rates of mortality and morbidity linked to genetic diseases support the need to implement plans to increase public awareness of the health burdens of consanguineous marriage. However, in some particular context, one should also consider the sociocultural benefits of such marriages. Pre-marital carrier testing, genetic counseling and PND should be essential parts of the care of PID patients and their families. However, these measures should be undertaken with respect to the social and religious practices of each community. The introduction of NBS programs for PIDs will facilitate early diagnosis and improve long-term survival for these disorders.

\section{References}

-1 Rezaei N, Notarangelo LD, Aghamohammadi A: Primary Immunodeficiency Diseases: Definition, Diagnosis, and Management. Berlin, Springer, 2008.

-2 Gennery AR, Slatter MA, Grandin L, et al: Transplantation of hematopoietic stem cells and long-term survival for primary immunodeficiencies in Europe: entering a new century, do we do better? J Allergy Clin Immunol 2010;126:602-610.e1-e11.

>3 Al-Herz W, Bousfiha A, Casanova JL, Chapel $\mathrm{H}$, Conley ME, Cunningham-Rundles C, Etzioni A, Fischer A, Franco J, Geha R, Hammarstrom L, Nonoyama S, Notarangelo LD, Ochs HD, Puck J, Roifman CM, Seger R, Tang $\mathrm{M}$ : Primary immunodeficiency diseases: an update on the classification from the International Union of Immunological Societies Expert Committee for Primary Immunodeficiency. Front Immunol 2011;2:1-26.

4 Boyle JM, Buckley RH: Population prevalence of diagnosed primary immunodeficiency diseases in the United States. J Clin Immunol 2007;27:497-502.

5 Bousfiha AA, Jeddane L, Ailal F, Benhsaien I, Mahlaoui N, Casanova JL, Abel L: Primary immunodeficiency diseases worldwide: more common than generally thought. J Clin Immunol 2013;33:1-7.

$>6$ Al-Herz W, Naguib KK, Notarangelo LD, Geha RS, Alwadaani A: Parental consanguinity and the risk of primary immunodeficiency disorders: report from the Kuwait National Primary Immunodeficiency Disorders Registry. Int Arch Allergy Immunol 2011;154:7680.

7 Rezaei N, Pourpak Z, Aghamohammadi A, et al: Consanguinity in primary immunodeficiency disorders; the report from Iranian Pri- mary Immunodeficiency Registry. Am J Re- 15 Denic S, Nagelkerke N, Agarwal MM: On prod Immunol 2006;56:145-151.

$>8$ Hamamy H, Antonarakis SE, Cavalli-Sforza LL, et al: Consanguineous marriages, pearls and perils: Geneva International Consanguinity Workshop Report. Genet Med 2011; 13:841-847.

$\checkmark 9$ Bittles A, Black ML: Evolution in health and medicine Sackler colloquium: consanguinity, human evolution, and complex diseases. Proc Natl Acad Sci USA 2010;107:17791786.

10 Sheridan E, Wright J, Small N, Corry PC, Oddie S, Whibley C, Petherick ES, Malik T, Pawson N, McKinney PA, Parslow RC: Risk factors for congenital anomaly in a multiethnic birth cohort: an analysis of the Born in Bradford study. Lancet 2013, DOI: 10.1016/ S0140-6736(13)61132-0.

$\checkmark 11$ Carothers AD, Rudan I, Kolcic I, Polasek O, Hayward C, Wright AF, Campbell H, Teague P, Hastie ND, Weber JL: Estimating human inbreeding coefficients: comparison of genealogical and marker heterozygosity approaches. Ann Hum Genet 2006;70:666-676.

12 Ben Halim N, Ben Alaya Bouafif N, Romdhane L, et al: Consanguinity, endogamy, and genetic disorders in Tunisia. J Community Genet 2013;4:273-284.

13 Barbouche MR, Galal N, Ben-Mustapha I, Jeddane L, Mellouli F, Ailal F, Bejaoui M, Boutros J, Marsafy A, Bousfiha AA: Primary immunodeficiencies in highly consanguineous North African populations. Ann NY Acad Sci 2011;1238:42-52.

14 Bittles AH: Time to get real: investigating potential beneficial genetic aspects of consanguinity. Public Health Genomics 2011;14: 169-171. some novel aspects of consanguineous marriages. Public Health Genomics 2011;14:162168.

16 Al-Herz W: Primary immunodeficiency disorder in Kuwait: first report from Kuwait National Primary Immunodeficiency Registry (20042006). J Clin Immunol 2008;28:186-193.

17 Al-Tamemi S, Elnour I, Dennison D: Primary immunodeficiency diseases in Oman: five years' experience at Sultan Qaboos University Hospital. World Allergy Organ J 2012;5:52-56.

18 Leiva LE, Zelazco M, Oleastro M, et al: Primary immunodeficiency diseases in Latin America: the second report of the LAGID registry. J Clin Immunol 2007;27:101-108.

19 Naidoo R, Ungerer L, Cooper M, Pienaar S, Eley BS: Primary immunodeficiencies: a $27-$ year review at a tertiary paediatric hospital in Cape Town, South Africa. J Clin Immunol 2011;31:99-105.

20 Ishimura M, Takada H, Doi T, Imai K, Sasahara Y, Kanegane H, Nishikomori R, Morio T, Heike T, Kobayashi M, Ariga T, Tsuchiya S, Nonoyama S, Miyawaki T, Hara T: Nationwide survey of patients with primary immunodeficiency diseases in Japan. J Clin Immunol 2011;31:968-976.

21 Gathmann B, Goldacker S, Klima M, et al: The German national registry for primary immunodeficiencies (PID). Clin Exp Immunol 2013;173:372-380.

22 Al-Herz W, Al-Mousa H: Combined immunodeficiency: the Middle East experience. J Allergy Clin Immunol 2013;131:658-660.

23 Segal BH, Leto TL, Gallin JI, Malech HL, Holland SM: Genetic, biochemical, and clinical features of chronic granulomatous disease. Medicine 2000;79:170-200. 
24 Fattahi F, Badalzadeh M, Sedighipour L, et al: Inheritance pattern and clinical aspects of 93 Iranian patients with chronic granulomatous disease. J Clin Immunol 2011;31:792-801.

-25 Bakri FG, Martel C, Khuri-Bulos N, Mahafzah A, El-Khateeb MS, Al-Wahadneh AM, Hayajneh WA, Hamamy HA, Maquet E, Molin M, Stasia MJ: First report of clinical, functional, and molecular investigation of chronic granulomatous disease in nine Jordanian families. J Clin Immunol 2009;29:215-230.

-26 Aghamohammadi A, Abolhassani H, Moazzami K, Parvaneh N, Rezaei N: Correlation between common variable immunodeficiency clinical phenotypes and parental consanguinity in children and adults. J Investig Allergol Clin Immunol 2010;20:372-379.

-27 Rivoisy C, Gérard L, Boutboul D, Malphettes M, Fieschi C, Durieu I, Tron F, Masseau A, Bordigoni P, Alric L, Haroche J, Hoarau C, Bérézné A, Carmagnat M, Mouillot G, Oksenhendler E; for the DEFI study group: Parental consanguinity is associated with a severe phenotype in common variable immunodeficiency. J Clin Immunol 2012;32:98-105.

-28 Al-Herz W, Zainal ME, Alenezi HM, Husain $\mathrm{K}$, Alshemmari SH: Performance status and deaths among children registered in Kuwait National Primary Immunodeficiency Disorders Registry. Asian Pac J Allergy Immunol 2010;8:141-146.

29 Al-Herz W, Moussa MA: Survival and predictors of death among primary immunodeficient patients: a registry-based study. J Clin Immunol 2012;32:467-473.

30 Villa A, Sobacchi C, Notarangelo LD, et al: $\mathrm{V}(\mathrm{D}) \mathrm{J}$ recombination defects in lymphocytes due to RAG mutations: severe immunodeficiency with a spectrum of clinical presentations. Blood 2001;97:81-88.

- 31 Dorman SE, Picard C, Lammas D, Heyne K, van Dissel JT, Baretto R, Rosenzweig SD, Newport M, Levin M, Roesler J, Kumararatne D, Casanova JL, Holland SM: Clinical features of dominant and recessive interferon gamma receptor 1 deficiencies. Lancet 2004;364: 2113-2121.

-32 Jin Y, Mazza C, Christie JR, Giliani S, Fiorini M, Mella P, Gandellini F, Stewart DM, Zhu Q, Nelson DL, Notarangelo LD, Ochs HD: $\mathrm{Mu}-$ tation of the Wischott-Aldrich Syndrome Protein (WASP): hotspots, effect on transcription, and translation and phenotype/ genotype correlation. Blood 2004;104:40104019.

-33 Lopez-Herrera G, Tampella G, Pan-Hammarström Q, et al: Deleterious mutations in LRBA are associated with a syndrome of immune deficiency and autoimmunity. Am J Hum Genet 2012;90:986-1001.

-34 Abdollahpour H, Appaswamy G, Kotlarz D, Diestelhorst J, Beier R, Schäffer AA, Gertz EM, Schambach A, Kreipe HH, Pfeifer D, Engelhardt KR, Rezaei N, Grimbacher B, Lohrmann S, Sherkat R, Klein C: The phenotype of human STK4 deficiency. Blood 2012; 119:3450-3457.
35 van Montfrans JM, Hoepelman AIM, Otto S, van Gijn M, van de Corput $\mathrm{L}$, de Weger RA, Monaco-Shawver L, Banerjee PP, Sanders EAM, Jol-van der Zijde CM, Betts MR, Orange JS, Bloem AC, Tesselaar K: CD27 deficiency is associated with combined immunodeficiency and persistent symptomatic EBV viremia. J Allergy Clin Immunol 2012;129: 787-793.

36 Blaydon DC, Biancheri P, Di WL, Plagnol V, Cabral RM, Brooke MA, van Heel DA, Ruschendorf F, Toynbee M, Walne A, O’Toole EA, Martin JE, Lindley K, Vulliamy T, Abrams DJ, MacDonald TT, Harper JI, Kelsell DP: Inflammatory skin and bowel disease linked to ADAM17 deletion. N Engl J Med 2011;365:1502-1508.

37 Marrakchi S, Guigue P, Renshaw BR, et al: Interleukin-36-receptor antagonist deficiency and generalized pustular psoriasis. N Engl J Med 2011;365:620-628.

38 Sancho-Shimizu V, Pérez de Diego R, Lorenzo L, et al: Herpes simplex encephalitis in children with autosomal recessive and dominant TRIF deficiency. J Clin Invest 2011;121:48894902.

-39 Bogunovic D, Byun M, Durfee LA, et al: Mycobacterial disease and impaired IFN- $\gamma$ immunity in humans with inherited ISG15 deficiency. Science 2012;337:1684-1688.

-40 Huck K, Feyen O, Niehues T, Rüschendorf F, Hübner N, Laws HJ, Telieps T, Knapp S, Wacker HH, Meindl A, Jumaa H, Borkhardt A: Girls homozygous for an IL-2-inducible T cell kinase mutation that leads to protein deficiency develop fatal EBV-associated lymphoproliferation. J Clin Invest 2009;119: 1350-1358.

41 Stepensky P, Keller B, Buchta M, Kienzler AK, Elpeleg O, Somech R, Cohen S, Shachar I, Miosge LA, Schlesier M, Fuchs I, Enders A, Eibel H, Grimbacher B, Warnatz K: Deficiency of caspase recruitment domain family, member 11 (CARD11), causes profound combined immunodeficiency in human subjects. J Allergy Clin Immunol 2013;131:477485.

42 Morgan NV, Goddard S, Cardno TS, McDonald D, Rahman F, Barge D, Ciupek A, Straatman-Iwanowska A, Pasha S, Guckian M, Anderson G, Huissoon A, Cant A, Tate WP, Hambleton S, Maher ER: Mutation in the TCRa subunit constant gene (TRAC) leads to a human immunodeficiency disorder characterized by a lack of TCR $\alpha \beta+$ T cells. J Clin Invest 2011;121:695-702.

43 Jabara HH, Ohsumi T, Chou J, Massaad MJ, Benson H, Megarbane A, Chouery E, Mikhael R, Gorka O, Gewies A, Portales P, Nakayama T, Hosokawa H, Revy P, Herrod H, Le Deist F, Lefranc G, Ruland J, Geha RS: A homozygous mucosa-associated lymphoid tissue 1 (MALT1) mutation in a family with combined immunodeficiency. J Allergy Clin Immunol 2013;132:151-158.
44 Vilboux T, Lev A, Malicdan MC, et al: A congenital neutrophil defect syndrome associated with mutations in VPS45. New Eng J Med 2013;369:54-65.

45 Lanzi G, Moratto D, Vairo D, Masneri S, Delmonte O, Paganini T, Parolini S, Tabellini G, Mazza C, Savoldi G, Montin D, Martino S, Tovo P, Pessach IM, Massaad MJ, Ramesh N, Porta F, Plebani A, Notarangelo LD, Geha RS, Giliani S: A novel primary human immunodeficiency due to deficiency in the WASP-interacting protein WIP. J Exp Med 2012;209: 29-34.

46 Glocker EO, Kotlarz D, Boztug K, et al: Inflammatory bowel disease and mutations affecting the interleukin-10 receptor. N Engl J Med 2009;361:2033-2045.

- 47 Glocker EO, Frede N, Perro M, Sebire N, Elawad M, Shah N, Grimbacher B: Infant colitis - it's in the genes. Lancet 2010;376:1272.

48 Kotlarz D, Ziętara N, Uzel G, et al: Loss-offunction mutations in the IL-21 receptor gene cause a primary immunodeficiency syndrome. J Exp Med 2013;210:433-443.

$\checkmark 49$ Modell V, Gee B, Lewis DB, Orange JS, Roifman CM, Routes JM, Sorensen RU, Notarangelo LD, Modell F: Global study of primary immunodeficiency diseases (PI) - diagnosis, treatment, and economic impact: an updated report from the Jeffrey Modell Foundation. Immunol Res 2011;51:61-70.

50 Harris R: Genetic services in Europe. A comparative study of 31 countries by the concerted action on genetic services in Europe. Eur J Hum Genet 1997;5(suppl 2):1-220.

51 Sermon K, Van Steirteghem A, Liebaers 1: Preimplantation genetic diagnosis. Lancet 2004;363:1633-1641.

52 Puck JM: Laboratory technology for population-based screening for severe combined immunodeficiency in neonates: the winner is $\mathrm{T}$ cell receptor excision circles. J Allergy Clin Immunol 2012;129:607-616.

53 Morinishi Y, Imai K, Nakagawa N, et al: Identification of severe combined immunodeficiency by $\mathrm{T}$-cell receptor excision circles quantification using neonatal guthrie cards. J Pediatr 2009; 155:829-833.

54 Borte S, von Döbeln U, Fasth A, Wang N, Janzi M, Winiarski J, Sack U, Harström Q, Borte M, Hammarström L: Neonatal screening for severe primary immunodeficiency diseases using high-throughput triplex real-time PCR. Blood 2012;119:2552-2555.

-55 Verbsky JW, Baker MW, Grossman WJ, Hintermeyer M, Dasu T, Bonacci B, Reddy S, Margolis D, Casper J, Gries M, Desantes K, Hoffman GL, Brokopp CD, Seroogy CM, Routes JM: Newborn screening for severe combined immunodeficiency; the Wisconsin experience (2008-2011). J Clin Immunol 2012;32:82-88

56 Chan K, Davis J, Pai SY, Bonilla FA, Puck JM, Apkon M: A Markov model to analyze costeffectiveness of screening for severe combined immunodeficiency (SCID). Mol Genet Metab 2011;104:383-389.
Consanguinity and Primary

Immunodeficiencies
Hum Hered 2014;77:138-143 DOI: $10.1159 / 000357710$ 